\title{
МЕТОДОЛОГИЯ НЕКЛАССИЧЕСКИХ И ПОСТНЕКЛАССИЧЕСКИХ ИССЛЕДОВАНИЙ СОЦИАЛЬНОГО ПРОСТРАНСТВА
}

\author{
Демидова Марина Владимировна, \\ demidovamv@rambler.ru \\ Россия, г. Энгельс
}

Демидова Марина Владимировна, кандидат философских наук, свободный исследователь.

\begin{abstract}
Актуальность. Разночтения в неклассических и постнеклассических трактовках социального пространства, представляющего собой теоретико-методологический конструкт, затрудняют изучение процессов структурирования и функционирования современного общества. Цель: определить значимость методологии, применяемой в неклассических и постнеклассических исследованиях социального пространства. Объектом является социальное пространство, предметом - методология исследований социального пространства. Методологическую базу данной работы составили: периодизация этапов развития науки по В.С. Стёпину, характеристика периодов развития науки по С.А. Лебедеву, социосинергетический и компаративный подходы, философия трансдисциплинарности. Впервые с методологических позиций проанализированы идеи о социальном пространстве, принадлежащие зарубежным и отечественным исследователям (П. Бурдье, Г. Зиммелю, Э. Дюркгейму, П. Сорокину, Э. Гидденсу, Л.А. Беляевой и др.). Выявлено преобладание классической методологии в работах Э. Дюркгейма, неклассической - Э. Гидденса, Г. Зиммеля, постнеклассической - П. Бурдье и Л.А. Беляевой. Основные идеи исследователей раскрываются с помощью таких понятий, как территория, структура социального пространства, социальные взаимодействия, дистанции, дифференциация, мобильность, иерархия, стратификация, динамика, круги (поля), подпространства, практики, капиталы, статус. Сделаны выводы об обусловленности дисциплинарных трактовок используемой авторами научной методологией; о проведении современных исследований социального пространства на основе дисциплинарных и междисциплинарных подходов, что затрудняет его познание. Результаты: в качестве перспективы впервые предложена идея применения альтернативной (трансдисциплинарной) методологии изучения социального пространства, развиваемой на основе системы координат Р. Декарта. Применение данной методологии позволяет проводить исследования по параметрам (статическим и динамическим), присущим всем системам. В то же время её преимущество состоит в возможности объединять разрозненные знания в единую концептуальную систему.
\end{abstract}

Ключевые слова: Неклассическая наука, постнеклассическая наука, методология, социальное пространство, трансдисциплинарная методология, трансдисциплинарная матрица, Р. Декарт.

Социальное пространство представляет собой теоретико-методологический конструкт, необходимый для изучения общества и интерпретируемый исследователями многозначно по причине принадлежности учёных к различным историческим эпохам и научной специализации. Он возник примерно на рубеже XIX-XX вв. у философов и социологов, изучавших общество в аспектах его структурирования и функционирования. Научно-дисциплинарная принадлежность исследователей повлияла на различное понимание социального пространства, что делает проблематичным его познание современными исследователями.

В то же время важным для истолкования данного конструкта является период в развитии науки - классический (XVII - конец XIX вв.), неклассический (с конца XIX в. до 70-х гг. XX в.) и постнеклассический (с 70-х гг. XX в. до начала XXI в.). Каждый из данных периодов отличается свойственными ему научными ценностями, парадигмами, 
методами, а это значит, что от приверженности исследователей тем или иным методологическим идеалам зависит понимание социального пространства.

Согласно В.С. Стёпину, разделение периодов науки на классический, неклассический и постнеклассический обусловлено, во-первых, типом системной организации исследуемых объектов, во-вторых, пониманием идеалов и норм исследования, в-третьих, изменением философских оснований науки [1]. В связи с чем для классической науки характерна ориентация на исследование простых систем, при этом условия объективности знания не связаны с познающим субъектом, процесс познания обусловлен только способностями человека. Неклассическая наука изучает сложные саморегулирующиеся системы, здесь учитывается роль средств и операций научно-исследовательской деятельности, выступающих в качестве посредника между разумом и объектом. В рамках постнеклассической науки исследуются сложные саморазвивающиеся системы; присутствует соотношение внутринаучных и вненаучных ценностей по причине социальной детерминированности любой деятельности, в том числе научной [1, с. 81-82; 2].

Научная методология, применяемая исследователями на каждом из этапов развития науки, также имеет свои особенности. Согласно С.А. Лебедеву, классическая наука отличается «разработкой методов открытия и доказательства объективно-истинного знания, неклассическая наука - разработкой методов открытия и обоснования вероятно-истинного знания об объектах, постнеклассическая наука характеризуется разработкой социальных технологий открытия и принятия полезных моделей и гипотез об объектах» [3, c. 2-3].

Данные методологические особенности следует учитывать при изучении социального пространства, его структуры и функционирования, т. к. от выбора методологии зависит результат исследования. Поэтому для понимания происходящих в современном обществе пространственных изменений следует провести анализ трактовок социального пространства с научно-методологических позиций.

К настоящему времени сложилась определённая традиция исследования социального пространства. Она представлена социальными науками, но не всеми: трактовки учёных-экономистов нами не обнаружены. Интерпретации данного понятия представлены в трудах таких известных социологов и философов, как Г. Зиммель, Э. Дюркгейм, П. Сорокин, Т. Парсонс, А. Лефевр, Э. Гидденс, П. Бурдье и других исследователей. Анализ идей некоторых из этих авторов поможет составить представление о современном социальном пространстве.

Наиболее активно социальное пространство изучается в рамках социологической науки. Одним из первых ещё в начале XX в. обратил своё внимание на пространственные аспекты существования общества Э. Дюркгейм (1858-1917), который, будучи приверженцем позитивистской научной традиции, основывал своё учение об обществе на понятии «социальный факт», понимаемый как «правила поведения, способы мышления, деятельности и чувствования, находящиеся вне индивида и наделённые принудительной силой, вследствие которой они ему навязываются» [4, с. 421]. Социальные факты изучаются с помощью «социальной морфологии» - учения, разработанного Э. Дюркгеймом. Суть данного учения сводится к следующему: общество есть масса людей, обладающая плотностью, расположенная на территории, где осуществляется социальное взаимодействие, обусловленное социальными фактами. Главной силой, объединяющей общество в целое, является солидарность [4]. Исходя из данных рассуждений, очевидна географическая трактовка социального пространства Э. Дюркгеймом, выраженная в идее эволюции общества, но реализованная в координатах линейного типа мышления, что характерно 
для классического типа рациональности, когда объект исследования изучается как простая система.

На принципиально иных - негеографических - основаниях развивал своё учение П. Сорокин (1889-1968), сосредоточившись на вопросах разделения иерархически расположенных слоёв в социальном пространстве [5, с. 298]. Тем самым П. Сорокин поставил вопрос о социальных дистанциях, основанных на сходствах и различиях в положении людей: чем больше сходств между людьми, тем меньшая дистанция их разделяет, и наоборот, наибольшие различия ведут к наибольшим социальным дистанциям. Точками отсчёта он предложил называть социальные признаки (принадлежность к государству, религии, профессии, полу, возрасту и др.).

Исходя из рассуждений о социальных дистанциях, П. Сорокин обосновал идею многомерности социального пространства [5, с. 300]. Многомерное пространство структурировано иерархически по признакам политической, экономической и профессиональной стратификации. Идея иерархического структурирования социального пространства привела П. Сорокина к выделению вертикальной и горизонтальной мобильностей как феноменов перемещения людей в этом пространстве [6]. Тем самым он смог найти взаимосвязь между статичной характеристикой пространства, какой является иерархически выстроенная структура, и динамическими (мобильными) параметрами, по которым функционирует социальное пространство. Это позволило ему объяснить основы социальной стратификации как положения человека в обществе, основанного на социальной позиции.

Методологически идеи П. Сорокина сложно идентифицировать однозначно как принадлежащие к классическому или неклассическому типам рациональности, т. к. им обоснована идея классической линейной социальной иерархии, которая синтезирована с неклассическим нелинейным пониманием динамики социального пространства. В то же время в идеях П. Сорокина наблюдается тенденция к рассмотрению объекта исследования как сложной системы. Это выражено в отрицании одной единственной причины социальной динамики и в применении интегративного подхода к исследованию социальных процессов, суть которого состоит в интегрировании принципов и способов организации теоретических и эмпирических социологических знаний.

Идеи П. Сорокина о дистанциях в социальном пространстве нашли своё продолжение в теории структурации Э. Гидденса (1938 г.р.). Эта теория построена на основе критики марксистской методологии и в целом учения К. Марса [7]. Э. Гидденс отстаивал научно-методологические идеи позитивизма, ставшие фундаментом сформированного им структурного подхода к исследованию общественных процессов [8]. Согласно его позиции, понимание общества не следует ограничивать деятельностью его субъектов, т. к. «структуральные свойства социальной системы существуют ... во времени и пространстве» [9, с. 15]. В пространстве-времени субъекты осуществляют социальные практики, разделённые на два плана - «передний» и «задний». Такое разделение позволило Э. Гидденсу объяснить особенности функционирования социальных индивидов относительно деятельности социальных институтов, осуществляющих её благодаря людям, имеющим передний и задний планы поведенческих практик. Именно практики «заднего плана» обеспечивают дистанцию между официальным и неофициальным пониманием социальных процессов. Отсюда следует идея Э. Гидденса о различии между центром и периферией в социальном пространстве, утверждающая неравномерность развития регионов социального пространства: «Те, кто занимает центральные зоны, “устанавливают" контроль за ресурсами, позволяющими сохранять дистанцию между ними и людьми с “периферии”» [9, с. 201]. 
В методологическом аспекте теория структурации Э. Гидденса представляет собой реализацию неклассических принципов рациональности, но обоснованных им только в эмпирическом аспекте, т. е. в выявлении фактов реальности в процессе структурации социального пространства. Теоретическое объяснение закономерностей выявленных эмпирических фактов Э. Гидденс не предложил. Присутствует рассмотрение объекта исследования как сложной системы.

Социально-философская традиция исследования социального пространства представлена учениями Г. Зиммеля и П. Бурдье.

Многие из изложенных выше идей социологов берут своё начало в философском исследовании Г. Зиммеля (1858-1918), поставившего ещё на рубеже XIX-XX вв. вопросы, связанные с изучением структуры и динамики социального пространства, определённого им как пространство, освоенное человеком, имеющее свои границы, разделённое на зоны действия и взаимодействия людей. При этом Г. Зиммель исходил из представлений о пространстве, принадлежащих философу И. Канту: «пространство обладает всей реальностью ... потому, что оно - форма и условие наших эмпирических представлений» $[10$, с. 54]. Это понимание впоследствии было элиминировано Г. Зиммелем в сферу социальной действительности, что позволило ему разработать основы учения о социальных дистанциях, первоначально представленного его рассуждениями о социальных кругах, в которых функционирует индивид: «Число различных кругов, к которым принадлежит отдельный человек, является... одним из показателей высоты культуры... Если современный человек принадлежит прежде всего к семейству своих родителей, потом к семье, основанной им самим...; если, далее, он принадлежит своему профессиональному кругу, что уже само по себе часто включает его в несколько кругов с различными интересами» [11, с. 412-413].

Идеи о социальных дистанциях Г. Зиммель развивал во взаимосвязи с изменениями в духовной жизни общества рубежа XIX-XX вв., констатировав увеличение социальных дистанций в больших городах, несмотря на территориальную скученность населения, чем выявил закономерность социального дистанцирования: территориальная социальная близость ещё не означает социальной целостности. Привязанность социальных образований к месту является проявлением пространственной локализации как важнейшей характеристики идентичности. В локальное социальное пространство встроено хозяйство с элементами торговли и производства, а также деньги как абстракции обмена, выражающие социальные отношения [12], которые по мере своего развития увеличивают пространственное дистанцирование, т. к. обладание деньгами усиливает мобильность и уменьшает зависимость от пространства.

С методологических позиций социально-философское учение Г. Зиммеля есть попытка изучения онтологии социального пространства: при анализе социальных феноменов им выявлены и объяснены некоторые закономерности социальных процессов. В то же время в идеях Г. Зиммеля наблюдается тенденция к рассмотрению общества как сложной системы, что соответствует неклассическому пониманию объекта исследования.

Особенностью концепции социального пространства П. Бурдье (1930-2002) является её фундаментально-прикладная направленность, реализуемая посредством структурно-функционального подхода, позволившего П. Бурдье определить социальное пространство как «структуру рядоположенности социальных позиций», т. е. среду, в которой осуществляются социальные отношения. Его место «может быть охарактеризовано через его относительное положение по сравнению с другими местами (выше, ниже, между и др.) и через дистанцию, отделяющую это место от других» [13, с. 49-50]. Социальное деление 
в пространстве функционирует как «ментальная структура» [13, с. 51], т. к. социальное пространство есть не физическое, а «абстрактное пространство, конституированное ансамблем подпространств или полей (экономическое поле, интеллектуальное поле и др.), которые обязаны своей структурой неравному распределению отдельных видов капитала» - экономического, культурного, социального [14]. Их ценность определяется благодаря символическому капиталу, который становится ключевым в этой борьбе между социальными группами (классами) за господство [15, с. 28-29]. Позиции агентов в социальном пространстве определяются социальными практиками, определяемыми как «наблюдаемые способы действий индивидов и социальных групп» [16, с. 32], социум структурирован посредством практик. Другими словами, социальное пространство, согласно П. Бурдье, динамично и изменчиво, оно имеет подпространства, образованные посредством социальных практик и структурированные отношениями социальных позиций.

Фундаментально-прикладная направленность, реализуемая с помощью структурно-функционального подхода, позволила П. Бурдье определить взаимосвязь статичных (структурных) и динамичных (функциональных) аспектов деятельности социальных субъектов. Методологически концепцию социального пространства, предложенную П. Бурдье, можно смело идентифицировать как соответствующую идеалам постнеклассической рациональности, когда происходит осмысление причин самоорганизации изучаемых систем, понимаемых как сложные, имеющие нелинейную структуру. Присутствует попытка создания объяснительных гипотез выявленных эмпирических закономерностей, обосновывается социальная детерминированность экономической, политической и других видов деятельности человека в обществе.

Современный отечественный социолог Л.А. Беляева, синтезировав на основе социально-философского учения П. Бурдье идеи Г. Зиммеля, Э. Дюркгейма, П. Сорокина, Т. Парсонса, Э. Гидденса и других исследователей, создала свою концепцию социального пространства, определяемого ей как «совокупность социальных статусов и дистанций, выраженных через группу эмпирических индикаторов и индексов, отражающих социальный статус входящих в него социальных акторов» [17, с. 60]. Данная концепция центрирована на понятии «социальная дистанция», понимаемом как «объективно-субъективное понятие, когда... различия между объективной действительностью и субъективной видимостью отражаются в самой субъективной видимости» $[17$, с. 63]. Социальные дистанции, являясь основным показателем социальной дифференциации, подвижны, обеспечивают социальную мобильность и влияют на образование структуры статусов в обществе. Причина возникновения социальных дистанций институциональная. Она представляет собой стремление к поддержанию социального статуса. Для измерения социальной дистанции Л.А. Беляева предложила воспользоваться «сравнением социальных статусов индивидов и групп согласно обладанию ими разными объемами капитала - экономического, культурного, социального и символического», как они представлены в интерпретации П. Бурдье [17, с. 64]. Общество уравновешено и социально контролируемо, если в нём присутствует баланс статусов и дистанций $[17$, с. 58].

Методологически концепция Л.А. Беляевой соответствует нормам и принципам постнеклассической науки, когда общество исследуется как сложная нелинейная система, устанавливаются причины процессов социального взаимодействия и социального структурирования, предлагается модель эмпирического исследования выявленных процессов. Но оно является дисциплинарным - социологическим исследованием.

Социолог Т.Ю. Петрова определила понятие «социальное пространство» как «комплекс социальных связей и отношений, процесс социального взаимодействия, 
определяющий основные характеристики сообществ и тенденцию их изменений» [18, с. 15]. Данная позиция основана на результатах применения структурной методологии к исследованию процессов формирования социального пространства, применяемой, однако, с позиций идеалов классической науки ввиду характеристики линейного иерархического строения социального пространства. В то же время анализ процессов акторного конструирования социального пространства позволил допустить Т.Ю. Петровой возможность социальной самоорганизации, что соответствует неклассическому пониманию вопросов функционирования общества, осуществлённому в эмпирическом (дисциплинарном социологическом) аспекте.

В целом отечественные научные исследования социального пространства находятся на стадии своего становления и развиваются на основе идей упомянутых выше зарубежных социологов и философов, поэтому отличаются применением преимущественно классической и неклассической методологии. Лишь некоторые из современных отечественных исследований проводятся в аспектах постнеклассической науки с учётом процессов социальной самоорганизации и различных аспектов её реализации. В их числе: 1) междисциплинарные исследования, направленные на выявление отдельных свойств социального пространства и специфику его организации [19]; 2) аспектные исследования, проводимые преимущественно в русле изучения социокультурных аспектов пространства [20]; 3) исследования трансформационных процессов современного социального пространства, нацеленные на изучение преимущественно двух видов трансформации - глобализацию социального пространства [21] и социальное интернет-пространство [22].

Таким образом, проведённый анализ основных теорий и концепций социального пространства позволяет сделать вывод об обусловленности трактовок данных авторов применяемой ими методологией. Выявлено преобладание классической методологии в работах Э. Дюркгейма, неклассической методологии исследования - в работах Э. Гидденса, Г. Зиммеля, постнеклассической методологии - в исследованиях П. Бурдье и Л.А. Беляевой. Синтез классической и неклассической методологии представлен в трудах П. Сорокина. В исследованиях П. Бурдье и Л.А. Беляевой присутствует реализация постнеклассического идеала рациональности, основывающегося на позиции, согласно которой «результат взаимодействия субъекта и объекта взаимодействия зависит от процесса их взаимодействия» [23, с. 70]. В целом отечественные научные исследования социального пространства находятся на стадии своего становления, лишь некоторые из них проводятся в аспектах постнеклассической науки. Основные идеи исследователей раскрываются с помощью следующих понятий: территория, социальное взаимодействие, социальные дистанции, структура социального пространства, социальная дифференциация, социальная мобильность, социальная иерархия, социальная стратификация, социальная динамика, социальные круги (поля), подпространства, социальные практики, капиталы, социальный статус.

Особенностью социологической методологии является установление эмпирических фактов социальной организации. Но объяснение функционирования установленных эмпирических фактов остаётся для социологии более сложной задачей, решение которой возможно на основе знания принципов и законов социальной жизни, что более плодотворно представлено в социально-философских исследованиях социального пространства, основные из которых - учения Г. Зиммеля и П. Бурдье, представивших социальнофилософские интерпретации социального пространства. Другими словами, существующие на сегодняшний день исследования социального пространства ведутся на основе 
дисциплинарных и междисциплинарных подходов, что делает проблематичным познание процессов социального структурирования и функционирования.

В связи с данным выводом считаем плодотворным в дальнейших исследованиях социального пространства применение трансдисииплинарного подхода, реализация которого, по мнению исследователей, вызывает множество сложностей, связанных с неоднозначным пониманием трансдисциплинарности и, как следствие, с выбором методологии, необходимой для его реализации [24]. Предпосылкой возникновения трансдисциплинарного подхода стала философия холизма, развитая в начале XX в. на основе «Метафизики» древнегреческого философа Аристотеля, согласно которому «целое больше, чем сумма его частей». В неклассической и постнеклассической философии холизм развивался с позиций системного подхода, что и позволило изучать объекты как системы. Система, определяемая как совокупность взаимосвязанных, взаимозависимых и взаимообусловленных элементов, стала базовым понятием трансдисциплинарного подхода, т. к. ей присущ дисциплинарный универсализм, означающий, что любой объект может изучаться как система, а с позиций постнеклассической науки - как самоорганизующаяся система.

Термин «трансдисциплинарность» был впервые предложен в 1970 г. швейцарским психологом и философом Жаном Пиаже, согласно которому научные исследования, проводимые с позиций подхода, который выходит за дисциплинарные и междисциплинарные рамки, могли бы быть более эффективными [25]. Последующее осмысление данной идеи происходит в смысловом поле, очерченном Ж. Пиаже, и опирается на понимание трансдисциплинарной методологии, специфика которой состоит в распространении этой методологии на такие исследования, «которые идут “через”, “сквозь” дисциплинарные границы, выходя “за пределы” конкретных дисциплин» [26, с. 35]. Такая методология позволяет дополнить новое знание предыдущим, «вступая в коэволюцию, формируя своеобразное “интенсивное измерение” исследуемого» [27, с. 173]. Согласно Б. Николеску, трансдисциплинарность рассматривается как принцип интеграции знаний, который определяется универсальными формальными структурами или моделями на основе плюралистических процессов и их динамики [28].

Исходя из этих идей, напрашивается предположение о том, что если суть трансдисциплинарного подхода состоит в выявлении знаний, выходящих за дисциплинарные пределы, и одновременно знаний, присущих всем научным дисциплинам, то такие знания образуют собой матрицы показателей (параметров знаний), которые было бы правильнее назвать «трансдисциплинарные матрицы» и определить их как динамически-статические матрицы, характеризующие системы в параметрах статики и динамики. В философско-категориальном смысле статические и динамические параметры есть характеристики пространства (оформленной структуры) и времени (последовательности событий) системы.

В связи с данной логикой давно известная и активно используемая в научных исследованиях система координат философа эпохи Нового времени Р. Декарта могла бы быть признана трансдисциплинарной матрицей. Эта система стала началом новой эпохи научного познания, поскольку позволила связать воедино теоретические и естественные науки. Их взаимосвязь теперь стала возможной, благодаря методологическим разработкам Р. Декарта, которые схематично представлены его системой координат и которые позволили графически наглядно изображать природные процессы (или в более узкой терминологии - физические, химические, социальные и др.), а также вычислять пространственные и временные параметры этих процессов. 
При этом характеристики реально расположенных в пространстве и времени объектов (место, границы, площадь, скорость, расстояние и др.) благодаря символизированию их человеком при помощи понятия «функция» переводятся в условные спекулятивные формы, необходимые в процессе мышления человека [29]. Создание подобной системы координат стало возможным, благодаря тому, что Р. Декарт считал математику наукой о пространственных образах и их измерении, при этом отвергая идею о самодостаточности принципов логики и математики, а все процессы в природе сводил к пространственному перемещению [30]. Другими словами, своей системой координат Р. Декарт создал иллюстративную модель мышления, которая делает возможным научное пространственное и временное восприятие и осмысливание тех или иных явлений, вещей или идей. Он предложил способ описания воспринимаемой человеком природной реальности.

Система координат Р. Декарта представляет собой «трансдисциплинарную матрицу», определяемую как «динамически-статическая матрица, характеризующая развитие и самоорганизацию системы в параметрах статики и динамики. Разработка трансдисциплинарной методологии исследования социального пространства, развиваемая на основе системы координат Р. Декарта, является философской методологией, соответствует идеалам и принципам постнеклассической науки и позволяет проводить исследования по параметрам - статическим и динамическим, присущим всем системам» [29, с. 190]. В то же время её преимущество состоит в возможности объединять разрозненные знания в единую концептуальную систему.

Таким образом, анализ дисциплинарной методологии, применяемой в неклассических и постнеклассических исследованиях социального пространства, показал неоднозначность его понимания исследователями. Понимаемое по-разному социальное пространство затрудняет изучение процессов структурирования и функционирования общества. В результате автором предложено новое решение, ранее неприменяемое по отношению к исследованию социального пространства, - трансдисциплинарный подход, в перспективе развиваемый на основе системы координат Р. Декарта. Она представляет собой «трансдисциплинарную матрицу», определяемую как динамически-статическая матрица, характеризующая развитие и самоорганизацию системы в параметрах статики и динамики. Преимущество её применения состоит в возможности объединять разрозненные знания в единую концептуальную систему знаний об исследуемом объекте (в данном случае - о социальном пространстве).

\section{СПИСОК ЛИТЕРАТУРЫ}

1. Стёпин В.С. Особенности научного познания и критерии типов научной рациональности // Эпистемология и философия науки. - 2013. - Т. XXXVI. - № 2. - С. 78-91.

2. Демидова M.B. Постнеклассическая аналитическая методология социальных наук: SWOT-анализ, PEST-анализ, дискурс-анализ // Гуманитарные научные исследования. - 2016. - № 11. URL: http://human.snauka.ru/2016/11/17422 (дата обращения 07.02.2020).

3. Лебедев С.А. Классическая, неклассическая и постнеклассическая методология науки // Гуманитарный вестник. - 2019. - Вып. 2. URL: http://dx.doi.org/10.18698/2306-8477-2019-2-596 (дата обращения 05.02.2020).

4. Дюркгейм Э. О разделении общественного труда. Метод социологии - М.: Наука, 1991. -575 с.

5. Сорокин П.А. Социальная и культурная мобильность // Человек. Цивилизация. Общество. - М.: Политиздат, 1992. - С. 256-309.

6. Sorokin P. Social mobility. - New York: Harper and Brothers, 1927. - 559 p.

7. Giddens A. A contemporary critique of historical materialism. - Stanford, Calif.: Stanford univ. press, 1995. $294 \mathrm{p}$.

8. Giddens A. New rules of sociological method: a positive critique of interpretative sociologies. - New York: Basic Books, Inc., 1976. - 192 p. 
9. Гидденс Э. Устроение общества. Очерк теории структурации. - М.: Академический Проект, 2005. $525 \mathrm{c}$.

10. Зиммель Г. Кант. 16 лекций, прочитанных в Берлинском университете // Избранное. Т. 1. Философия культуры. URL: http://filosof.historic.ru/books/item/f00/s00/z0000079/index.shtml (дата обращения 05.02.2020)

11. Зиммель Г. О скрещении социальных кругов // Избранное. Т. 2. Созерцание жизни. - М.: Юрист, 1996. - C. 412-428.

12. Simmel G. The philosophy of money. URL: http://www.eddiejackson.net/web_documents/Philosophy\% 20of\%20Money.pdf (дата обращения 07.02.2020).

13. Бурдье П. Социология социального пространства. - М.: Институт экспериментальной социологии; СПб.: Алетейя, 2007. - 288 с.

14. Bourdieu P. Ökonomisches Kapital, kulturelles Kapital, soziales Kaputal // Soziale Ungleichheiten (Soziale Welt, Sonderheft 2) / Ed. by R. Kreckel. - Güttingen: Otto Schwartz \& Co., 1983. - P. 183-198.

15. Демидова М.В. «Символический капитал» П. Бурдье и «Капитал» К. Маркса // Вестник Вятского государственного гуманитарного университета. - 2014. - № 11. - С. 27-32.

16. Беляева Л. А. Социальное пространство: от теоретических построений к эмпирическому изучению // Философские науки. - 2012. - № 6. - С. 22-35.

17. Беляева Л.А. Социальные дистанции как характеристика социального пространства современной России // Вестник РУДН. Серия «Социология». - 2018. - Т. 18. - № 1. - С. 58-72. DOI: 10.22363/23132272-2018-18-1-58-72.

18. Петрова Т.Ю. Социальное пространство как процесс: автореф. дис. ... канд. социол. наук. - Нижний Новгород, 2003. - 22 с.

19. Нагайцев В.В., Пустовалова Е.В. Опыт методологии исследования социального пространства человека: междисциплинарный подход // Вестник НГУЭУ. - 2018. - № 4. - С. 207-213.

20. Грязнова Е.В., Афанасьев С.В. К вопросу об определении понятия «социокультурное пространство» // Современные исследования социальных проблем. - 2019. - Т. 11. - № 2-1. - С. 27-41.

21. Докумова Л.Ш. Глобализация как процесс самоорганизации социального пространства: синергетическая интерпретация // Экономические и гуманитарные исследования регионов. - 2016. - № 4. C. $72-75$.

22. Минина В.Н., Василькова В.В. От социального пространства к пространству онлайн социальных сетей: исследовательские подходы и вызовы // Социальное пространство. - 2019. - № 5 (22). - С. 1-15. DOI: $10.15838 / \mathrm{sa} .2019 .5 .22 .10$.

23. Демидова М.В. Инновационное пространство и общество: понятия, факторы развития // Векторы благополучия: экономика и социум. - 2019. - № 3 (34). - C. 64-78. URL: http://jwt.su/ journal/issue/view/36 (дата обращения 01.02.2020). DOI: 10.18799/24056537/2019/3(34)/981.

24. Мокий М.С., Мокий В.С. Трансдисциплинарность в высшем образовании: экспертные оценки, проблемы и практические решения // Современные проблемы науки и образования. - 2014. - № 5. URL: https://www.science-education.ru/ru/article/view?id=14526 (дата обращения 07.02.2020).

25. Piaget J. L'épistémologie des relations interdisciplinaires. URL: http:/www.fondationjeanpiaget.ch/fjp/ site/textes/VE/jp72_epist_relat_interdis.pdf (дата обращения 01.02.2020).

26. Князева Е.Н. Трансдисциплинарная когнитивная стратегия в науке будущего // Вызов познанию: стратегия развития науки в современном мире. - М.: Наука, 2004. - С. 29-49.

27. Богатая Л. Трансдисциплинарность: постнеклассический ракурс рецепции // Філософія освіти. Philosophy of Education. - 2015. - № 1 (16). - C. 168-182.

28. Nicolescu B. The transdisciplinary evolution of the university condition for sustainable development // Transdisciplinary Theory, Practice and Education. - Cham: Springer, 2018. - P. 73-81.

29. Демидова М.В. Трансдисциплинарность и «продолженная система координат Р. Декарта» // Философия инноваций и социология будущего в пространстве культуры: научный диалог: сборник статей Всероссийской научно-практической конференции с международным участием (г. Уфа, 10 декабря 2020). Часть I / отв. ред. Р.М. Валиахметов. - Уфа: РИЦ БашГУ, 2020. - С. 184-191.

30. Декарт Р. Избранные произведения. - М.: Политиздат, 1950. - 712 с.

Поступила 13.10.2020 г. 
UDC 1:316.25:167

\title{
METHODOLOGY OF NON-CLASSICAL AND POST-NON-CLASSICAL STUDIES OF SOCIAL SPACE
}

\author{
Marina V. Demidova, \\ demidovamv@rambler.ru \\ Engels, Russia
}

Marina V. Demidova, Cand. Sc., free researcher.

Discrepancies in non-classical and post-non-classical interpretations of social space, which is a theoretical and methodological construct, make it difficult to study the processes of structuring and functioning of modern society. The aim of the research is to determine the significance of the methodology used in non-classical and post-non-classical studies of social space. The object is the social space, the subject is the methodology of social space research. The methodological basis of this work: the periodization of science development stages according to V.S. Stepin, characteristics of the periods of science development according to S.A. Lebedev, sociosynergetic and comparative approaches, philosophy of transdisciplinarity. The ideas of P. Bourdieu, G. Simmel, E. Durkheim, P. Sorokin, E. Giddens, and L.A. Belyaeva were analyzed from a methodological point of view. The predominance of classical methodology in the works of E. Durkheim, non-classical research methodology in the works of E. Giddens, G. Simmel, and post-non-classical methodology in the studies of P. Bourdieu and L.A. Belyaeva were revealed. The main ideas of researchers are revealed using such concepts as territory, social space structure, social interactions, distances, differentiation, mobility, hierarchy, stratification, dynamics, circles (fields), subspaces, practices, capitals, status. The author has drawn conclusions on the conditionality of disciplinary interpretations of the scientific methodology used by the authors, on the conduct of modern research of social space on the basis of disciplinary and interdisciplinary approaches, which makes it difficult to understand it. As a perspective, the author first proposed the idea of using an alternative-transdisciplinary methodology for studying social space, developed on the basis of the coordinate system of $R$. Descartes. The use of this methodology allows us to conduct research on parameters - static and dynamic, inherent in all systems. At the same time, it has the advantage of being able to combine disparate knowledge into a single conceptual system.

Key words: Non-classical science, post-non-classical science, methodology, social space, transdisciplinary methodology, transdisciplinary matrix, R. Descart.

\section{REFERENCES}

1. Stepin V.S. Osobennosti nauchnogo poznaniya i kriterii tipov nauchnoy ratsionalnosti [Features of scientific knowledge and criteria for types of scientific rationality]. Epistemologiya i filosofiya nauki, 2013, vol. XXXVI, no. 2, pp. 78-91.

2. Demidova M.V. Postneklassicheskaya analiticheskaya metodologiya sotsialnykh nauk: SWOT-analiz, PESTanaliz, diskurs-analiz [Post-non-classical analytical methodology of social Sciences: SWOT analysis, PEST analysis, discourse analysis]. Gumanitarnye nauchnye issledovaniya, 2016, no. 11. Available at: http://human.snauka.ru/2016/11/17422 (accessed 7 February 2020).

3. Lebedev S.A. Klassicheskaya, neklassicheskaya i postneklassicheskaya metodologiya nauki [Classical, nonclassical and post-non-classical methodology of science]. Gumanitarny vestnik, 2019, Iss. 2. Available at: http://dx.doi.org/10.18698/2306-8477-2019-2-596 (accessed 5 February 2020).

4. Dyurkgeim E. O razdelenii obshchestvennogo truda. Metod sotsiologii [On the division of social labor. Method of Sociology]. Moscow, Nauka Publ., 1991. 575 p.

5. Sorokin P.A. Sotsialnaya i kulturnaya mobilnost [Social and cultural mobility]. Chelovek. Tsivilizatsiya. Obshchestvo [Person. Civilization. Society]. Moscow, Politizdat Publ., 1992. pp. 256-309.

6. Sorokin P. Social mobility. New York, Harper and Brothers, 1927. 559 p. 
7. Giddens A. A contemporary critique of historical materialism. Stanford, Calif., Stanford univ. press, 1995. $294 \mathrm{p}$.

8. Giddens A. New rules of sociological method: a positive critique of interpretative sociologies. New York, Basic Books, Inc., 1976. 192 p.

9. Giddens E. Ustroenie obshchestva. Ocherk teorii strukturatsii [The Constitution of Society. Outline of the Theory of Structuration]. Moscow, Akademicheskiy Proekt Publ., 2005. 525 p.

10. Zimmel G. Kant. 16 lektsii, prochitannykh v Berlinskom universitete [Kant. 16 lectures delivered at the University of Berlin]. Izbrannoe. T. 1. Filosofiya kultury [Selected writings. Vol. 1. Philosophy of culture]. Available at: http://filosof.historic.ru/books/item/f00/s00/z0000079/index.shtml (accessed 5 February 2020).

11. Zimmel G. O skreshchenii sotsialnykh krugov [About the intersection of social circles]. Izbrannoe. T. 2. Sozertsanie zhizni [Selected writings. Vol. 2. Contemplation of life]. Moscow, Yurist Publ., 1996. pp. 412-428.

12. Simmel G. The philosophy of money. Available at: http://www.eddiejackson.net/web_documents/Philosophy \%20of\%20Money.pdf (accessed 07 February 2020).

13. Burde P. Sotsiologiya sotsialnogo prostranstva [Sociology of social space]. Moscow, Institut eksperimentalnoy sotsiologii Publ.; St. Petersburg, Aleteya Publ., 2007. 288 p.

14. Bourdieu P. Economic capital, cultural capital, social capital. Social inequalities [Social World, special issue 2]. Ed. by R. Kreckel. Güttingen, Otto Schwartz \& Co., 1983. pp. 183-198.

15. Demidova M.V. «Simvolicheskiy kapital» P. Burde i «Kapital» K. Marksa [«Symbolic capital» by P. Bourdieu and «Capital» by K. Marx]. Vestnik Vyatskogo gosudarstvennogo gumanitarnogo universiteta, 2014, no. 11, pp. 27-32.

16. Belyaeva L.A. Sotsialnoe prostranstvo: ot teoreticheskikh postroeniy k empiricheskomu izucheniyu [Social space: from theoretical constructions to empirical study]. Filosofskie nauki, 2012, no. 6, pp. 22-35.

17. Belyaeva L.A. Sotsialnye distantsii kak kharakteristika sotsialnogo prostranstva sovremennoy Rossii [Social distances as a characteristic of the social space of modern Russia]. Vestnik RUDN. Seriya «Sotsiologiya», 2018, vol. 18, no. 1, pp. 58-72. DOI: 10.22363/2313-2272-2018-18-1-58-72.

18. Petrova T.Yu. Sotsialnoe prostranstvo kak protsess. Avtoref. Dis. Kand. nauk [Social space as a process. Dis. Kand. Abstract]. Nizhny Novgorod, 2003. 22 p.

19. Nagaytsev V.V., Pustovalova E.V. Opyt metodologii issledovaniya sotsialnogo prostranstva cheloveka: mezhdistsiplinarny podkhod [Experience in the methodology of human social space research: an interdisciplinary approach]. Vestnik NGUEU, 2018, no. 4, pp. 207-213.

20. Gryaznova E.V., Afanasev S.V. K voprosu ob opredelenii ponyatiya «sotsiokulturnoe prostranstvo» [On the issue of defining the concept of «socio-cultural space»]. Sovremennye issledovaniya sotsialnykh problem, 2019, vol. 11 , no. 2-1, pp. 27-41.

21. Dokumova L.Sh. Globalizatsiya kak protsess samoorganizatsii sotsialnogo prostranstva: sinergeticheskaya interpretatsiya [Globalization as a process of self-organization of social space: a synergetic interpretation]. Ekonomicheskie i gumanitarnye issledovaniya regionov, 2016, no. 4, pp. 72-75.

22. Minina V.N., Vasilkova V.V. Ot sotsialnogo prostranstva k prostranstvu onlayn sotsialnykh setey: issledovatelskie podkhody i vyzovy [From social space to online social network space: research approaches and challenges]. Sotsialnoe prostranstvo, 2019, no. 5 (22), pp. 1-15. DOI: 10.15838/sa.2019.5.22.10.

23. Demidova M.V. Innovative space and society: definitions, development factors. Journal of Wellbeing Technologies, 2019, no. 3 (34), pp. 64-78. In Rus. DOI: 10.18799/24056537/2019/3(34)/981. Available at: http://jwt.su/journal/issue/view/36 (accessed 1 February 2020).

24. Mokiy M.S., Mokiy V.S. Transdistsiplinarnost v vysshem obrazovanii: ekspertnye otsenki, problemy i prakticheskie resheniya [Transdisciplinarity in higher education: Expert assessments, problems and practical solutions]. Sovremennye problemy nauki i obrazovaniya, 2014, no. 5. Available at: https://www.science-education.ru/ru/article/view?id=14526 (accessed 7 February 2020).

25. Piaget Jn. The epistemology of interdisciplinary relations. Available at: http://www.fondationjeanpiaget. ch/fjp/site/textes/VE/jp72_epist_relat_interdis.pdf (accessed 01 February 2020).

26. Knyazeva E.N. Transdistsiplinarnaya kognitivnaya strategiya v nauke budushchego [Transdisciplinary cognitive strategy in the science of the future]. Vyzov poznaniyu: strategiya razvitiya nauki v sovremennom mire [Challenge to knowledge: strategy for the development of science in the modern world]. Moscow, Nauka Publ., 2004. pp. 29-49.

27. Bogataya L. Transdistsiplinarnost: postneklassicheskiy rakurs retseptsii [Transdisciplinarity: post-non-classical reception angle]. Philosophy of Education, 2015, no. 1 (16), pp. 168-182.

28. Nicolescu B. The transdisciplinary evolution of the university condition for sustainable development. Transdisciplinary Theory, Practice and Education. Cham, Springer, 2018. pp. 73-81.

29. Demidova M.V. Transdistsiplinarnost i «prodolzhennaya sistema koordinat R. Dekarta» [Transdisciplinarity and the «continued coordinate system of R. Descartes»]. Filosofiya innovatsiy i sotsiologiya budushchego $v$ 
prostranstve kultury: nauchny dialog. Sbornik statey Vserossiyskoy nauchno-prakticheskoy konferentsii s mezhdunarodnym uchastiem [Philosophy of Innovation and Sociology of the Future in the Space of Culture: Scientific Dialogue. Collection of Articles of the All-Russian Scientific and Practical Conference with International Participation]. Ed. by R.M. Valiakhmetov. Ufa, December 10, 2020. P. I. Ufa, RITs BashGU Publ., 2020. pp. 184-191.

30. Dekart R. Izbrannye proizvedeniya [Selected works]. Moscow, Politizdat Publ., 1950. 712 p.

Received: 13 October 2020. 